\title{
A expressão de condicionalidade na construção [caso + oração finita] no português do Brasil
}

DOI: http://dx.doi.org/10.21165/el.v49i2.2533

\section{Camila Fernandes da Silva'}

\section{Resumo}

Considerando que na categoria condicional encontra-se uma variedade de estruturas que podem expressar diferentes nuances de condicionalidade, busca-se compreender como traços da estrutura formal e aspectos semântico-pragmáticos da construção [caso + oração fınita] se relacionam para compor o significado condicional. Sob a perspectiva dos modelos baseados no uso, nossos pressupostos teóricos baseiam-se, especialmente, em Dancygier (1998) e Dancygier e Sweetser (2005). Os dados correspondem ao português brasileiro contemporâneo (séculos XX e XXI), extraídos do Corpus do Português.

Palavras-chave: parâmetros de condicionalidade; construção condicional; categorização.

1 Universidade Federal do Mato Grosso do Sul (UFMS), Três Lagoas, Mato Grosso do Sul, Brasil; camila.fernandes@ufms.br; https://orcid.org/0000-0002-4655-9067 


\title{
The meaning of conditionality in the construction [caso + finite clause] in Brazilian Portuguese
}

\begin{abstract}
Considering that in the conditional category it is found a variety of forms that can express different nuances of conditionality, we aim to understand how features of the formal and semantic-pragmatic aspects of the construction [caso + finite sentence] are related to compose the conditional meaning. Under a usage-based linguistics interpretation, our theoretical assumptions are based, in particular, on Dancygier (1998) and Dancygier and Sweetser (2005). The data correspond to contemporary Brazilian Portuguese $\left(20^{\text {th }}\right.$ and $21^{\text {st }}$ century), extracted from the Corpus do Português.
\end{abstract}

Keywords: parameters of conditionality; conditional construction, categorization.

\section{Considerações iniciais}

A caracterização dos conectores condicionais, bem como as estruturas por eles introduzidas, tem sido foco de interesse de diversos estudos. Dentre uma infinidade de trabalhos que tratam, sobretudo, do esquema "Se p, q", Hirata-Vale (2005) e Oliveira (2008, 2012 , 2014) mostram que para compreender a zona de condicionalidade é preciso abordála de modo mais amplo, focando não apenas nos elementos mais centrais da categoria, mas relacionando-os a membros mais periféricos. Isto porque, conforme demonstrado em Dancygier (1998), Ferrari (2000, 2015) e Oliveira e Hirata-Vale (2017), o significado condicional manifesta-se em um conjunto variado de nuances semântico-pragmáticas, o que nos mostra que em diferentes estruturas podemos encontrar funções distintas.

Nesse sentido, entende-se que a categoria condicional é uma categoria conceitual. Isto quer dizer que cada aspecto de forma e função envolvido na construção condicional (formas verbais, tipo de conector, posição, domínio cognitivo, etc.) pode afetar o modo como ela será compreendida (DANCYGIER, 1998). O significado condicional é, então, a manifestação da relação entre aspectos da estrutura linguística e traços de sua interpretação semântico-pragmática convencionalizados entre os usuários da língua (OLIVEIRA; HIRATA-VALE, 2017).

Com base nesses pressupostos, o objetivo aqui é descrever e analisar o esquema condicional [caso + oração finita] a fim de mostrar como sua estrutura formal e suas propriedades semântico-pragmáticas estão correlacionadas para compor o significado condicional. Este estudo segue uma orientação dos modelos baseados no uso, com base, principalmente, em Dancygier (1998), Dancygier e Sweetser (2005) e Bybee (2010), e considera a oração condicional como uma construção segundo postulados de Goldberg 
(1995), Croft (2001) e Traugott e Trousdale (2013). Partimos, assim, da concepção de que a língua é uma rede de construções em que significado e estrutura estão completamente relacionados e, portanto, não podem ser interpretados isoladamente. Desse modo, para este trabalho, consideramos o caráter complexo e multifacetado da categoria condicional na qual se abrigam tanto exemplares mais próximos do núcleo prototípico, sendo, desse modo, mais representativos, quanto exemplares mais distantes - portanto, menos prototípicos.

Para cumprir tal proposta, este artigo está organizado da seguinte forma: discutemse, inicialmente, as bases teóricas em que está alicerçada nossa análise. Em seguida, trazemos os aspectos metodológicos utilizados, para, enfim, caracterizarmos a construção introduzida por caso segundo os parâmetros de condicionalidade. As considerações finais mostram, de modo geral, como traços formais e funcionais interagem para a expressão de condicionalidade nas construções analisadas.

\section{Princípios Teóricos}

\section{Modelos baseados no uso}

Denominam-se modelos baseados no uso ou linguística funcional centrada no uso (LFCU) os estudos que, recentemente, têm entrelaçado propostas de pesquisadores funcionais e cognitivistas como Bybee, Traugott, Langacker, Fillmore, Fauconnier, Goldberg, entre outros. Nessa abordagem, a língua é vista como constantemente afetada pelo uso e pelo impacto que essa experiência tem sobre o sistema cognitivo (BYBEE, 2010). Acreditase que fenômenos estruturais observados na gramática das línguas naturais podem ser derivados de processos cognitivos de domínio geral. Processos de domínio geral, de acordo com Bybee (2010), seriam aqueles que se podem mostrar produtivos em outras áreas de cognição humana, não só na linguagem. Isto é, alguns dos mecanismos e habilidades cognitivas que levam à criação das estruturas linguísticas podem ser aplicáveis a outros domínios - como memória, percepção visual, categorização etc.

A partir dessa concepção, busca-se compreender não somente a estrutura linguística, mas os processos cognitivos envolvidos na criação das construções da língua, pois, "ao investigar os processos de domínio geral, nós não apenas estreitamos a busca por processos específicos à língua, mas também situamos a linguagem no contexto mais amplo do comportamento humano" (BYBEE, 2016, p. 26). Em outras palavras, acreditase que o modo como a língua se organiza pode ser explicado por fatores que vão além dos domínios da linguagem. Assim, nesta visão teórica, o processo de categorização é influenciado pela relação que o homem tem com a sua cognição, o mundo e a sociedade. Compreende-se o mundo não apenas em termos de coisas individuais, mas também em termos de categorias de coisas (FURTADO DA CUNHA; BISPO, 2013). Isso acontece inclusive na linguagem: assim como categorizamos o mundo biofísico e sociocultural, categorizamos a língua. 
Na categoria condicional, por exemplo, existe uma variedade de construções introduzidas por diferentes conectores, em que a condicional na estrutura "Se p q" é, pela nossa experiência, a construção prototípica. Vários membros ou propriedades que integram uma determinada categoria apresentam diferentes graus de saliência e são agrupados, basicamente, de acordo com a similaridade entre eles, sendo seus limites imprecisos, assim como os das diferentes categorias (LANGACKER, 2008; BYBEE, 2010). Nessa perspectiva, entende-se que a categorização é um processo cognitivo de domínio geral, uma vez que não ocorre apenas na linguagem, mas em outros âmbitos da nossa cognição.

Nesse sentido, há o reconhecimento do estatuto fundamental das funções da língua na descrição de suas formas, de modo que cada entidade linguística é definida em relação ao papel que ela desempenha nos processos reais de comunicação. Em razão disso, buscam-se, como objetos de análise, os esquemas gramaticais resultantes da convencionalização da relação entre estrutura linguística e sua interpretação semânticopragmática - também chamados construções gramaticais (FURTADO DA CUNHA; CEZÁRIO, 2013). É somente combinando as dimensões funcional e descritiva que chegamos a uma compreensão global dos fenômenos gramaticais (LANGACKER, 2008).

A escolha desta perspectiva teórica justifica-se por entendermos que a condicionalidade é uma categoria conceitual que abriga construções de diferentes estruturas. Desta forma, especificar as relações gramaticais em termos de construções justifica-se ao verificarmos que determinado item gramatical, como caso, por exemplo, pode aparecer em um número variado de construções diferentes, de modo que este item não é o bastante para determinar o significado que essa construção pode ter. Ao contrário, o significado de um item depende da composição da estrutura a qual está relacionado. Isto quer dizer que o conector caso, por si só, não habilita a expressão de condicionalidade, mas tal sentido provém da construção e da maneira como a construção se estrutura e se combina semanticamente com o conector para expressar um evento hipotético (GOLDBERG, 1995, 2006).

De modo geral, focalizamos os conceitos fundamentais da abordagem dos modelos baseados no uso, com a intenção de combinar forma e significado na análise da condicional encabeçada por caso, considerando de que modo os aspectos semânticos, discursivos e pragmáticos de uma dada construção contribuem para sua interpretação total. Além disso, neste modelo de descrição, é possível sistematizar as diversas formas de expressar a condicionalidade, corroborando suas motivações composicionais. Assim, a próxima seção é dedicada à construção condicional e à maneira como ela vem sendo caracterizada. 


\section{A categoria condicional}

A construção condicional é, geralmente, uma construção complexa que envolve uma cláusula nuclear (denominada apódose ou q) e uma cláusula subordinada ${ }^{2}$ ( $p$ ou prótase). A cláusula subordinada é introduzida por um conector, sendo prototípico o conector se (DANCYGIER, 1998). Em termos semânticos, uma construção condicional é aquela que se apoia, basicamente, numa hipótese; a relação que se instaura entre o conteúdo da prótase (entidade $p$ ) e o conteúdo da apódose (entidade q) é uma relação do tipo condição para realização consequência/resultado da resolução da condição enunciada (NEVES, 2000).

Para analisar as orações condicionais, Dancygier (1998) parte da noção de construção como postulada por Goldberg (1995). A construção refere-se ao padrão convencional existente no pareamento entre a forma linguística e sua interpretação, isto é, uma construção pode ser caracterizada segundo seus aspectos morfossintáticos em correlação com as propriedades semânticas e discursivas. Portanto, o foco de Dancygier (1998) é explicar quais características estruturais e funcionais estão mapeadas em aspectos de interpretação, de modo que sejam específicas da construção condicional. Para a autora, a expressão de condicionalidade é determinada pela convencionalização da correlação entre forma e significado que emergem das construções.

Ainda segundo Dancygier (1998), dentro da categoria condicional, existe um conjunto variado de construções em que algumas estão no centro - portanto, são mais representativas - e outras se encontram mais distantes do núcleo da categoria, sendo mais periféricas e menos categóricas. Nesse sentido, a autora assume a condicionalidade como uma categoria organizada a partir de parâmetros de condicionalidade. Por meio desses parâmetros, é possível entender como a categoria condicional está organizada e quais são os aspectos de forma e sentido centrais para a interpretação condicional, a fim de descobrir quais exemplares são mais prototípicos e quais estão mais afastados do protótipo da categoria.

Com base na proposta de Dancygier (1998), é preciso identificar e compreender não apenas como aspectos de forma e significado se associam para construir a interpretação condicional, mas mostrar quais são os traços específicos a que a condicionalidade está relacionada. Assim, é possível descobrir quais são as divergências existentes entre os tipos de condicionais, destacando quais são exatamente os pontos que as aproximam ou as distanciam da categoria condicional.

2 Como se vê em Halliday (1985), Matthiessen e Thompson (1988) e Hopper e Traugott (1993), a construção condicional é uma construção do tipo hipotática (subordinada adverbial) por ser uma estrutura menos dependente, semanticamente, e menos encaixada, sintaticamente, do que as construções substantivas e adjetivas; e mais dependente e encaixada do que a construção paratática (coordenada). 
Os parâmetros de condicionalidade referem-se, então, a um grupo de características que estão presentes na leitura condicional que são: a relação causal entre prótase e apódose, a função preditiva da condicional, a elaboração de espaços mentais hipotéticos e o distanciamento epistêmico do usuário da língua frente à proposição. Desse modo, quanto mais traços de condicionalidade uma construção apresenta mais perto da prototipia ela está, e, consequentemente, quanto mais restrito o contexto de atuação de uma construção condicional, menos categórica ela será, e, portanto, mais distante do núcleo prototípico.

Conforme exposto por Oliveira e Hirata-Vale (2017), considera-se que quanto mais convencionalizado estiver, entre os usuários da língua, o significado de condicionalidade de uma construção, mais próximo do núcleo prototípico ela se encontrará. Por sua vez, as estruturas que, para expressar o sentido condicional, precisam se amparar em aspectos pragmáticos, são construções que se encontram mais distantes da zona de condicionalidade, sendo, desse modo, construções que demonstram menos características de uma condicional prototípica. É o que se vê, por exemplo, nas ocorrências em (1) e (2) que mostram, respectivamente, uma construção introduzida por "se" - que corresponde à estrutura prototípica do português brasileiro, e uma construção mais periférica e menos representativa - iniciada por "exceto se":

(1) Se não tivesse ido buscar o advogado, não teria caído com a cara na pedra. (NEVES, 2000, p. 851)

(2) as duas camadas externas neuronais da retina geralmente permanecem sem lesões, exceto se oclusões vasculares estão superajuntadas. (OLIVEIRA, 2008, p. 85)

Oliveira e Hirata- Vale (2017) afirmam que a prototipia das condicionais introduzidas por se, como em (1), explica-se, uma vez que, nelas, estão presentes os traços mais básicos do significado de condicionalidade. As autoras mostram que essas construções aparecem em uma variedade de contextos, atuando em diversos domínios semântico-pragmáticos, até os mais abstratos e intersubjetivos. No entanto, construções como a exemplificada em (2), em que há, no conector, conteúdo lexical bastante concreto, como exceto se, são estruturas menos categóricas por ainda precisarem do contexto em que estão inseridas para a manifestação de sentido hipotético, e, portanto, não podem construir nuances mais abstratas do significado condicional, atuando em um número restrito de contextos formais e semântico-pragmáticos.

Em uma escala de prototipicidade, as condicionais introduzidas por caso estão muito próximas da construção nuclear; isto é, a construção condicional marcada pelo conector caso mantém traços formais e semântico-pragmáticos do padrão condicional mais básico iniciado por se, podendo atuar em uma gama de contextos, dos mais concretos 
aos mais (inter)subjetivos. No entanto, como se pretende demonstrar nesta análise, as construções com caso, mesmo atuando em um número variável de contextos, ainda conservam traços do seu significado lexical, podendo, desse modo, se distanciar do seu núcleo prototípico em alguns pontos.

\section{Metodologia}

Dada a orientação dos modelos baseados no uso, em que a gramática é concebida como organização cognitiva de experiências dos usuários com a língua (BYBEE, 2016), consideramos, para este estudo, estruturas linguísticas reais do português. Assim, para a presente análise, foram coletados dados da língua portuguesa brasileira contemporânea, do Corpus do Português (DAVIES; FERREIRA, 2006), disponível on-line (https://www. corpusdoportugues.org).Trata-se de um banco de dados que apresenta, atualmente, duas partes distintas: (i) corpus gênero/histórico (original e menor), que possibilita a visualização das mudanças históricas e as variações de gêneros; e (ii) corpus web/ dialetal (novo e muito maior), que permite verificar as variações dialetais (e há 50 vezes mais dados do português moderno).

Para a discussão que se propõe neste trabalho, seguimos um olhar qualitativo e sincrônico dos dados. A análise aqui realizada fixou-se nos trechos de diferentes tipos de textos do Corpus do Português (acadêmico, notícias, ficção, oral e textos da web) no português do Brasil nos séculos XX e XXI. A busca foi feita pelas construções em que caso introduz uma construção adverbial de expressão condicional. A partir daí, delimitamos 300 ocorrências para análise, devido a esse tipo de construção ser extremamente frequente nesse corpus.

As construções marcadas por caso foram analisadas de acordo com os traços de intepretação condicional proposto por Dancygier (1998), Dancygier e Sweetser (2005), que são: distância epistêmica, a relação causal estabelecida entre domínios cognitivos, o traço de predição e da elaboração de espaços mentais hipotéticos.

\section{A construção condicional [caso + oração finita]}

Neste trabalho, analisam-se as construções condicionais introduzidas por caso a fim de verificar quais são as características que permitem a expressão de condicionalidade. Consideram-se os parâmetros definidos por Dancygier (1998), segundo os quais a condicionalidade deve ser entendida conforme cada aspecto de forma e significado mapeado para construir a interpretação condicional. 


\section{Distância Epistêmica}

Dancygier (1998) propõe que um dos traços definidores da categoria condicional é apresentar um distanciamento epistêmico por parte do usuário da língua, uma vez que o sentido básico construído pelas construções condicionais parece estar embasado na falta de certeza do locutor frente às afırmações que realiza. Portanto, as condicionais são construídas com verbos e marcas linguísticas que, no geral, indicam uma situação futura, uma expectativa ou uma contraexpectativa do locutor e nunca uma situação que pode ser de fato assegurada por quem a emite.

A construção (3), exemplificada abaixo, pode ser considerada uma postura epistêmica neutra do usuário da língua sobre o evento descrito. Tendo em vista a configuração dos tempos verbais da construção condicional (futuro do subjuntivo, na prótase, e presente do indicativo + infınitivo, na apódose), pode-se perceber que o usuário da língua nem considera, nem desconsidera o conteúdo da prótase "comprometer os músculos respiratórios":

(3) Caso comprometer os músculos respiratórios, pode acontecer a morte, pelo fato de mudar a mecânica respiratória (Corpus do Português: G BR portalbrasil.net)

Já em (4), o usuário da língua considera o evento impossível de acontecer no mundo real, ao configurar o verbo no pretérito imperfeito do subjuntivo na prótase - "eu dissesse que choveu" -; logo, sua postura é negativa.

(4) Também me marcou o primeiro encontro com alguém de minha terra, que imediatamente perguntou se estava chovendo por lá. Caso eu dissesse que choveu, a volta seria possível. (Corpus do Português: 190r:Br:Intrv:ISP)

Em (5), a postura do usuário da língua pode ser considerada mais distanciada do que na ocorrência anterior. A perífrase verbal no pretérito imperfeito do subjuntivo + particípio (tivesse tomado) revela que o emissor se distancia negativamente da afirmação, pois não avalia o evento da condicional "caso tivesse tomado outra decisão" como algo que pode ser realizado.

(05) Mas sabe como é às vezes me pego pensando como seria minha vida caso tivesse tomado outra decisão, mas esse pensamento não é de Deus. (Corpus do Português: G BR apenas 1.wordpress.com) 
Um fator determinante para a verificação do parâmetro de distância epistêmica é a configuração modo temporal do verbo. Na ocorrência (3), o uso de futuro do modo subjuntivo, na prótase, sinaliza que o usuário da língua não tem conhecimento se o evento se realizará; portanto, apresenta uma visão neutra sobre a situação. Em (4) e (5), os verbos das condicionais estão configurados no pretérito imperfeito do subjuntivo; isso indica que o usuário da língua enxerga o evento descrito na prótase como algo que não é provável de acontecer.

Segundo Fillmore (1990), a postura epistêmica está relacionada à associação ou dissociação mental que o usuário da língua faz sobre o evento construído na prótase. Assim, no exemplo abaixo (6), temos uma postura epistêmica neutra: o usuário da língua não se associa mentalmente com a cena apresentada (a foto ser escolhida):

(06) Caso a sua foto seja escolhida, ela fará parte da próxima edição da revista abcDesign, assim como seu nome. (Corpus do Português: G BRabcdesign.com.br)

Na construção (6), o modo subjuntivo da prótase revela a imprecisão do conteúdo enunciado: o usuário da língua se distancia do que é dito, pois não afirma que a foto de seu interlocutor será escolhida, mas também não nega. Tal como demonstra Neves (2000), o modo subjuntivo indica menor grau de probabilidade de ocorrência da situação da construção condicional. Claramente, trata-se de uma hipótese construída pelo usuário da língua sobre uma situação que pode ou não ser realizada. Ou seja, a "sua foto" pode ser ou não escolhida. As formas verbais da construção em (6) - presente do subjuntivo, na prótase, e futuro do presente do indicativo, na apódose - são utilizadas quando o usuário da língua suspeita que o evento acontecerá.

Em uma situação de postura epistêmica negativa, por sua vez, há um grau maior de dissociação mental do usuário da língua, uma vez que ele não acredita que o episódio da condicional pode vir de fato a acontecer - não se trata de uma probabilidade futura, como no exemplo anterior. Observa-se na ocorrência (7) que a situação da prótase, "caso passasse", configura-se no pretérito imperfeito do subjuntivo; trata-se, então, de uma hipótese que não virá a ocorrer.

(07) Quanto ao modelo que deve ser estabelecido, deveria ser o mesmo que estava em curso no projeto do CPPB, que não foi a frente graças a lobby dos delegados de polícia, que acho que deveriam fazer lobby mesmo, pois caso passasse, com certeza não teriam muito o que fazer. (Corpus do Português: G BRabordagempolicial.com) 
Pode-se interpretar a construção em (7) como uma suposição de uma situação que não é realizada e nem será no futuro. O usuário da língua deixa claro, na construção anterior à condicional, que o projeto não foi à frente e supõe que, "caso passasse", a consequência seria de "não ter muito o que fazer". O comprometimento do usuário da língua com o evento contido na condicional é anulado, pois ele elabora uma construção em que é impossível o episódio incidir no mundo real. Conforme explicam Dancygier e Sweetser (2005), geralmente o uso de tempos de pretérito indica uma "distância" temporal e epistêmica. Em (7), o evento da condicional "caso passasse" não é somente improvável, mas também contrário ao fato da cláusula nuclear - "não foi a frente graças a lobby dos delegados de polícia". Conforme argumentam Dancygier e Sweetser (2005, p. 59, tradução nossa ${ }^{3}$ :

Dado que muitas vezes se supõe que os falantes sabem o que realmente aconteceu em uma situação passada, a posição epistêmica negativa em relação a uma eventualidade condicional no pretérito pode ser facilmente interpretada no sentido de que o falante pretende que a eventualidade seja vista como contrafactual.

Em uma postura epistêmica neutra, não há uma contradição como a apresentada em (7), mas sim uma previsão sobre um futuro esperado pelo usuário da língua que, contudo, ainda não foi realizado. Essas construções são classificadas como potenciais, visto que o evento descrito tem reais chances de ocorrer futuramente. A ocorrência abaixo é um exemplar desse tipo de construção potencial:

(8) Caso cumpras o que te peço, ser-te-ei mui grato no futuro. (Corpus do Português: 19:Fic:Br:Gomes:Rios)

Na construção (8), a condicional no presente do modo subjuntivo "caso cumpras o que te peço" é vista, pelo usuário da língua, como algo que ainda não foi concretizado e também não está certo que será realizado. Nesse caso, o locutor distancia-se da crença de que seu interlocutor fará o que ele pede, para não parecer arrogante ou autoritário. Tendo em vista que a apódose configura-se no tempo futuro do presente do modo indicativo, há uma expectativa por parte do usuário da língua de que este evento se realize, mesmo que a situação pareça incerta.

De fato, os dados aqui analisados corroboram a proposta de Dancygier e Sweetser (2005) de que as construções condicionais sinalizam postura epistêmica neutra ou negativa.

3 No original: "Given that speakers may often be assumed to know what actually happened in a past situation, negative epistemic stance towards a past conditional eventuality can readily be interpreted as meaning that the speaker intends that eventuality to be viewed as counterfactual". 
A condicional iniciada por caso é capaz de indicar postura epistêmica neutra, quando associada a tempos de presente e futuro do modo subjuntivo, e postura epistêmica negativa, ao ser configurada no tempo pretérito do modo subjuntivo. Desse modo, as condicionais introduzidas por caso expressam uma dissociação mental por parte do usuário da língua sobre o conteúdo da proposição.

\section{Causalidade e domínios cognitivos}

Sweetser (1990) e Dancygier (1998) avaliam que a expressão de causalidade da condicional se manifesta em diferentes domínios conceptuais: a) domínio de conteúdo; b) domínio epistêmico; c) domínio dos atos de fala e d) domínio metatextual.

A partir da análise de dados, verifica-se que as condicionais introduzidas por caso parecem poder atuar em qualquer um dos domínios cognitivos, como mostram os exemplos:

(9) Caso a vítima não seja resgatada a tempo, a morte se dará por afogamento secundário advindo do choque hipovolêmico provocado por a hemorragia. (Corpus do Português: G BR institutobotocinza.org)

(10) Caso ele não deseje disputar um novo mandato, nós temos alguns nomes dentro do partido que poderão representar bem o Estado. (Corpus do Português: 190r:Br:Intrv:Pov)

(11) Caso o senhor recebesse o convite para assumir a Secretaria de Segurança Pública, aceitaria? (Corpus do Português: 190r:Br:Intrv:Pov)

(12) A Casa de a Torre, da família Dias D'Ávila - poderosos cristãos novos - chegou a possuir milhares de quilômetros quadrados de terra, indo da Bahia ao Piauí, incluindo ainda trechos de Sergipe, partes da Capitania das Alagoas e pedaços de Pernambuco. Mais ainda, os da Casa da Torre eram cristãos novos - judeus convertidos a ferro e a fogo. Caso essa informação seja correta, Lula seria então um provável descendente de judeus. Logo ele, que arrasta a asa para os ditadores árabes. A vida é engraçada! (Corpus do Português: GBR radioislam.org)

De (9) a (12) estão exemplificadas, respectivamente, uma condicional de conteúdo, uma condicional epistêmica, uma condicional de atos de fala e uma condicional metatextual. É possível perceber no exemplo (9) que o significado de causalidade é a base para a estruturação dos eventos entre a prótase e a apódose; isto é, podemos verificar que a situação descrita na cláusula nuclear é desencadeada pelo evento codificado na 
condicional. As condicionais que pertencem ao domínio de conteúdo relacionam dois estados de coisas do mundo real; assim, configuram-se situações mais concretas e, portanto, a noção de causalidade, aqui, parece ser mais marcada do que em outros domínios conceptuais.

Conforme Dancygier (1998), o domínio epistêmico é caracterizado por conter uma relação entre premissas e perspectivas que o usuário da língua realiza através da condicional; por meio dessas premissas, o locutor realiza as conclusões expressas na cláusula nuclear. Assim, como se vê na ocorrência (10) parte-se de um conhecimento do fato, expresso na proposição da condicional "caso ele não deseje disputar um novo mandato", para concluir como uma verdade a expressão contida na cláusula nuclear "nós temos alguns nomes dentro do partido que poderão representar bem o Estado". Notase que há um posicionamento do usuário da língua que realiza uma avaliação sobre o evento da condicional. A relação de causa e consequência dá-se, aqui, no sentido de que a suposição contida na cláusula marcada por caso determina a conclusão descrita na cláusula nuclear. Tendo em vista que a condicional epistêmica tem a ver com a atitude do usuário da língua em relação a um espaço hipotético que é construído, pode-se afirmar que essas condicionais são mais abstratas do que as condicionais de domínio de conteúdo; consequentemente, a causalidade é diluída e passa a ser menos evidente.

Conforme demonstrado em (11), as construções marcadas pelo conector caso também são utilizadas como estratégia discursiva. Segundo Sweetser (1990), uma condicional de ato de fala pode ser explicada da seguinte maneira: considere $p$ e eu executo esse ato de fala. Ainda de acordo com a autora, a causalidade acontece uma vez que o que está descrito na prótase é entendido como o que está "causando" ou habilitando o ato de fala na apódose. A autora ainda destaca que os atos de fala são, de fato, realizados - e não apenas condicionalmente realizados. Nesse sentido, as condicionais de atos de fala não marcam uma relação estrita de causa-consequência, já que uma oração não está desencadeando outra; na verdade, a prótase é utilizada como motivadora para a o ato de fala enunciado na apódose. A condicional de atos de fala está relacionada com a situação interacional em que o usuário da língua considera relevante enunciar algo, e insere o seu interlocutor nesse enunciado.

Em (12), a condicional marcada por caso funciona para referenciar o que foi mencionado anteriormente na construção, de forma anafórica com o uso do pronome demonstrativo essa. O que se vê nessa construção, é que "caso essa informação seja correta" é pano de fundo para "Lula seria então um provável descendente de judeus". Assim, a condicional introduzida por caso pode ser usada como um comentário metatextual sobre algum aspecto da cláusula nuclear, demonstrando grau de intersubjetividade - uma vez que o usuário da língua pretende mostrar-se cooperativo com seu interlocutor. 
Vê-se assim que as condicionais aqui analisadas apresentam-se em diferentes domínios discursivos: o que se refere ao mundo concreto (em que se relacionam estados de coisas), ou o domínio conceptual de conteúdo; o epistêmico (referente à ligação de situações prováveis entre os eventos); o domínio de atos de fala (as relações intercomunicativas, em que a condicional é utilizada como pano de fundo para um ato de fala) e o domínio metatextual (nível mais intersubjetivo, em que a condicional é utilizada como recurso textual, de modo geral).

\section{Predição}

A predição, segundo Dancygier (1998), é outra característica central das condicionais. Na condicional preditiva, o evento da prótase é uma previsão para a ocorrência da apódose. É o que se nota na construção abaixo, marcada por combinações formadas a partir do presente do subjuntivo com o futuro do indicativo:

(13) Caso o empresário não consiga quitar as dívidas até o final deste ano, para regularizar sua situação em 2011 ele terá que fazer os pagamentos referentes aos anos de 2007, 2008, 2009 e 2010. (Corpus do Português: G BR4mail.com.br)

Além dos tempos presente e futuro, as construções correlacionadas aos tempos verbais no passado demonstram o traço de predição, como exemplificado em (14):

(14) Caso a ausência de satélites continuasse, a população teria que enfrentar novos desafios diariamente. (Corpus do Português: G BR megacurioso.com.br)

$\mathrm{Na}$ construção (14), formada com o pretérito imperfeito do subjuntivo, na prótase (continuasse), e o futuro do pretérito do indicativo, na apódose (teria), a semântica dos verbos difere da referência temporal construída pelo usuário da língua. Em outras palavras, os verbos em tempos de pretérito veiculam situações que se referem a eventos futuros. Há, nessas situações, um recuo temporal (backshifting), que ocorre quando a referência temporal antecede o acontecimento indicado pelo verbo. Dancygier (1998) explica que a predição é presente, nesses casos, porque o usuário da língua utiliza tempos de pretérito para sinalizar uma situação que poderia ter acontecido se o evento enunciado na cláusula condicional tivesse, de fato, ocorrido; portanto, seria também um caso de previsão que o usuário da língua faz ao relacionar uma sequencialidade entre os eventos da prótase e apódose. 
Em contraposição, há as condicionais não preditivas que, como delineia Dancygier (1998, p. 128, tradução nossa"), "são livres na sua escolha de formas verbais e são geralmente não distanciadas e não causais sobre o nível proposicional". Nesse caso, não existe uma indicação de um evento futuro; as formas verbais da construção não expressam predição, uma vez que estão relacionadas a tempo implicado ou habitualidade. Como a apresentada abaixo:

(15) - Está bem, aceito, caso o carro esteja disponível. (Corpus do Português: 19: Fic:Br:Vieira:Mais)

Assim, observamos que a predição - traço fundamental para a expressão de condicionalidade - também é uma característica que faz parte do significado da condicional introduzida pelo conector caso.

\section{Elaboração de espaços mentais hipotéticos}

A partir de Fauconnier (1985, p. 16, tradução nossa5), Dancygier (1998) assinala que "espaços mentais são construtos distintos das estruturas linguísticas, mas construídos de acordo com as diretrizes fornecidas pelas expressões linguísticas". Em linhas gerais, quando falamos ou pensamos, construímos um espaço mental no qual, por meio de um espaço base, outros espaços mentais podem ser construídos. Nesse sentido, em construções condicionais é possível verificar que, a partir de algumas expressões específicas (como o conector e a configuração modo-temporal), denominadas construtores espaciais, instauram-se novos espaços ou se referem aos espaços que já foram estabelecidos na construção (DANCYGIER; SWEETSER, 2005).

Vejamos como a rede de espaços mentais configura-se nas condicionais com caso:

(16) Caso o consumidor não tenha utilizado os serviços durante todos os meses do ano anterior, terá ele o direito da declaração de quitação dos meses em que houve faturamento dos débitos. (Corpus do Português: G BR2 viadeconta.com.br)

A condicional em (16) representa duas configurações alternativas de espaço mental, ambas interpretadas como futuros potenciais do atual espaço base descrito na construção. Assim, existe um espaço base "o consumidor não utilizar os serviços / ter o direito da

4 No original: "Non-predictive conditionals, on the other hand, are free in their choice of verb forms and are generally not distanced and not causal on the propositional level".

5 No original: "Mental spaces are constructs distinct from linguistic structures but built up in any discourse according to guidelines provided by the linguistic expressions". 
declaração de quitação" a partir do qual se constroem dois espaços: espaço fundação "o consumidor não utilizar os serviços e ter o direito da declaração" - e espaço expansão - "o consumidor utilizar os serviços e não ter o direito da declaração". Como explicam Dancygier e Sweetser (2005), a escolha do conector e das formas verbais, entre outros aspectos da construção condicional, é uma implicação para construir uma perspectiva a partir de um ponto de vista espacial particular ou de um papel participante específico na interação da fala. Sendo assim, a partir da construção [caso + oração finita], o usuário da língua elabora um espaço mental hipotético em que os acontecimentos descritos na proposição podem ser alternados e codificados em diferentes domínios conceptuais.

\section{Considerações finais}

O foco deste trabalho foi demonstrar as especificidades semântico-pragmáticas da construção condicional introduzida pelo conector caso e como elas se relacionam com traços formais - como marcações verbais - para expressar condição. A partir deste estudo, foi possível observar que a construção condicional [caso + oração finita] apresenta características que estão na base do significado condicional tal como propõe Dancygier (1998) e Oliveira e Hirata-Vale (2017). Nota-se que esta construção correlaciona traços formais específicos para que características como predição, distância epistêmica e elaboração de espaços mentais hipotéticos possam ser codificadas, como, por exemplo, o uso exclusivo do modo subjuntivo do verbo.

O motivo pelo qual a condicional introduzida por caso não é utilizada no modo indicativo pode ser explicado pela própria semântica do nome caso - que, em outros contextos significa acontecimento, fato, situação realizada - sentido este que, de certo modo, se distancia das condicionais. Tal conector parece ser resultado de construcionalização (TRAUGOTT; TROUSDALE, 2013), isto é, caso que ora se comporta como um nome passa, também, a atuar como conector de uma construção condicional (SILVA, em andamento).

Entende-se, portanto, que caso somente pode ser caracterizado como um conector que introduz uma construção condicional quando esquematizado com determinadas formas temporais - especificamente aquelas que indicam incerteza, predição e traços de futuridade. Assim, vê-se que a construção introduzida por caso apresenta especificidades estruturais e conceptuais para a expressão do significado condicional.

\section{Agradecimentos}

Esta pesquisa é parte da dissertação de mestrado da autora, a qual foi realizada com apoio da Coordenação de Aperfeiçoamento de Pessoal de Nível Superior - Brasil (CAPES) - Demanda Social. A autora é membro do Grupo de Estudos Sociofuncionalistas. 


\section{REFERÊNCIAS}

BYBEE, J. Language, usage and cognition. Cambridge: Cambridge University Press, 2010.

BYBEE, J. Língua, uso e cognição. Tradução Maria Angélica Furtado da Cunha. São Paulo: Cortez, 2016.

CROFT, W. Radical Construction grammar: syntactic theory in typological perspective. Oxford: Oxford University Press, 2001.

DANCYGIER, B. Conditionals and predication (Cambridge Studies in Linguistics). Cambridge: Cambridge University Press, 1998.

DANCYGIER, B.; SWEETSER, E. Mental spaces in grammar: conditional constructions. Cambridge: Cambridge University Press, 2005. (Cambridge Studies in Linguistics, 108).

DAVIES, M.; FERREIRA, M. Corpus do Português. 2006. Disponível em: http://www. corpusdoportugues.org. Acesso em: 10 abr. 2018.

FAUCONNIER, G. Mental spaces: aspects of meaning construction in natural language. Cambridge: MIT Press, 1985.

FERRARI, L. Os parâmetros básicos da condicionalidade na visão cognitivista. Veredas, v. 4 , n. 1, p. 21-30, 2000.

FERRARI, L. Semântica Objetivista ou Semântica Cognitiva? Implicações do modelo semântico em análise de condicionais. Gragoatá, Niterói, n. 38, p. 142-162, 2015.

FILLMORE, C. Epistemic stance and grammatical form in English conditional sentences. In: ZIOLKOWSKI, M.; NOSKE, M.; DEATON, K. (ed.). Papers from the 26th Regional Meeting of the Chicago Linguistic Society. Chicago: Chicago Linguistic Society, 1990. p. 137-162.

FURTADO DA CUNHA, M. A.; BISPO, B. E. Pressupostos teórico-metodológicos e categorias analíticas da linguística funcional centrada no uso. Revista do GELNE, Natal/ RN, v. 15, n. esp., p. 53-78. 2013.

FURTADO DA CUNHA, M. A.; BISPO, B. E. et al. Linguística funcional centrada no uso: conceitos básicos e categorias analíticas. In: FURTADO DA CUNHA, M. A.; BISPO, B. E.; CEZÁRIO, M. M. Linguística centrada no uso. Rio de Janeiro: Mauad, 2013. p. 13-40. 
GOLDBERG, A. E. Constructions at work: the nature of generalization in language. Oxford: Oxford University Press, 2006.

GOLDBERG, A. E. A construction grammar approach to argument structure. Chicago/ London: The University of Chicago Press, 1995.

HIRATA-VALE, F. B. M. A expressão da condicionalidade no português escrito do Brasil: contínuo semântico-pragmático. 2005. Tese (Doutorado em Linguística e Língua Portuguesa) - Faculdade de Ciências e Letras, Universidade Estadual Paulista "Júlio de Mesquita Filho", Araraquara, 2005.

LANGACKER, R. W. Cognitive Grammar: A basic introduction. Oxford: Oxford University Press, 2008.

OLIVEIRA, T. P. Conjunções e orações condicionais no português do Brasil. 2008. Tese (Doutorado em Linguística e Língua Portuguesa) - Faculdade de Ciências e Letras, Universidade Estadual Paulista "Júlio de Mesquita Filho", Araraquara, 2008.

OLIVEIRA, T. P. As conjunções condicionais na Gramática Discursivo Funcional. In: SOUZA, E. R. F. Funcionalismo linguístico: análise e descrição. São Paulo: Contexto: 2012. p. 119-146.

OLIVEIRA, T. P. Conjunções adverbiais no português. Revista de Estudos Linguísticos, Belo Horizonte, v. 22, n. 1, p. 45-66, jan./jun. 2014.

OLIVEIRA, T. P.; HIRATA-VALE, F. B. M. A condicionalidade como zona conceitual. Delta, São Paulo, v. 33, n. 1, p. 291-313, 2017.

NEVES, M. H. M. Gramática de usos do português. São Paulo: Editora UNESP, 2000.

SWEETSER, E. From etymology to pragmatics: metaphorical and cultural aspects of semantic structure. (Cambridge Studies in Linguistics, 54). Cambridge: Cambridge University Press, 1990.

TRAUGOTT, E. C.; TROUSDALE, G. G. Constructionalization and Constructional Change. Oxford: Oxford University Press, 2013. 